\section{\$10. Creep Properties of V-4Cr-4Ti Strengthened by Cold Working and Aging}

Zheng, P.F. (Grad. Univ. Advanced Studies), Nagasaka, T., Muroga, T., Li, Y.F., Chen, J.M. (Southwestern Institute of Physics)

Vanadium alloys are attractive candidate materials for application in the first-wall and selfcooled liquid blanket of fusion reactors. $\mathrm{V}-4 \mathrm{Cr}-4 \mathrm{Ti}$ is the current reference composition. Though a lot of progresses have been made for this kind of vanadium alloy, the high temperature strength should be enhanced further to raise the operation temperature and thermal efficiency of the reactor. This study focused on some thermo-mechanical treatments for strengthening $\mathrm{V}-4 \mathrm{Cr}-4 \mathrm{Ti}$ alloys, such as NIFS-HEAT-2 and SWIP-11 shown in Table 1.

Table 1: The compositions of V-4Cr-4Ti alloys

\begin{tabular}{|c|c|c|c|c|l|l|}
\hline Element/wt\% & $\mathrm{V}$ & $\mathrm{Cr}$ & $\mathrm{Ti}$ & $\mathrm{C}$ & $\mathrm{N}$ & $\mathrm{O}$ \\
\hline SWIP-11 & Bal. & 3.76 & 4.05 & 0.011 & 0.001 & 0.057 \\
\hline NIFS-H-2 & Bal. & 4.02 & 3.98 & 0.0069 & 0.0122 & 0.0148 \\
\hline
\end{tabular}

The main difference between the two alloys is oxygen concentration. It is 570wppm for SWIP-11, while $148 \mathrm{wppm}$ for NIFS-HEAT-2. The thermomechanical treatment conditions were:

STD: standard heat treatment as $1000^{\circ} \mathrm{C} / 2 \mathrm{hrs}$ for vanadium alloys;

SAA: solid solution annealing at $1100^{\circ} \mathrm{C} / 1 \mathrm{hr}+$ aging at $600^{\circ} \mathrm{C} / 20 \mathrm{hrs}$;

SAACW: solid solution annealing at $1100^{\circ} \mathrm{C} / 1 \mathrm{hr}$ + aging at $600^{\circ} \mathrm{C} / 20 \mathrm{hrs}+20 \%$ cold working;

SACWA: solid solution annealing at $1100^{\circ} \mathrm{C} / 1 \mathrm{hr}$ $+20 \%$ cold working + aging at $600^{\circ} \mathrm{C} / 20 \mathrm{hrs}$.

Then, hardness tests were performed at room temperature. Uniaxial creep tests were carried out at $700^{\circ} \mathrm{C}$ and $750^{\circ} \mathrm{C}$ on a creep machine as Figure 1. Microstructure observations were conducted by a transmission electron microscope (TEM).

The $20 \%$ cold working hardened the alloys.

The cold-worked alloy was hardened further by the following aging. Aging time to reach the maximum hardness for the cold-worked alloy was longer than that without cold working. The reason of longer aging time may be the lower trapping rate of $\mathrm{C}, \mathrm{O}$, and $\mathrm{N}$ by Ti under high density dislocations

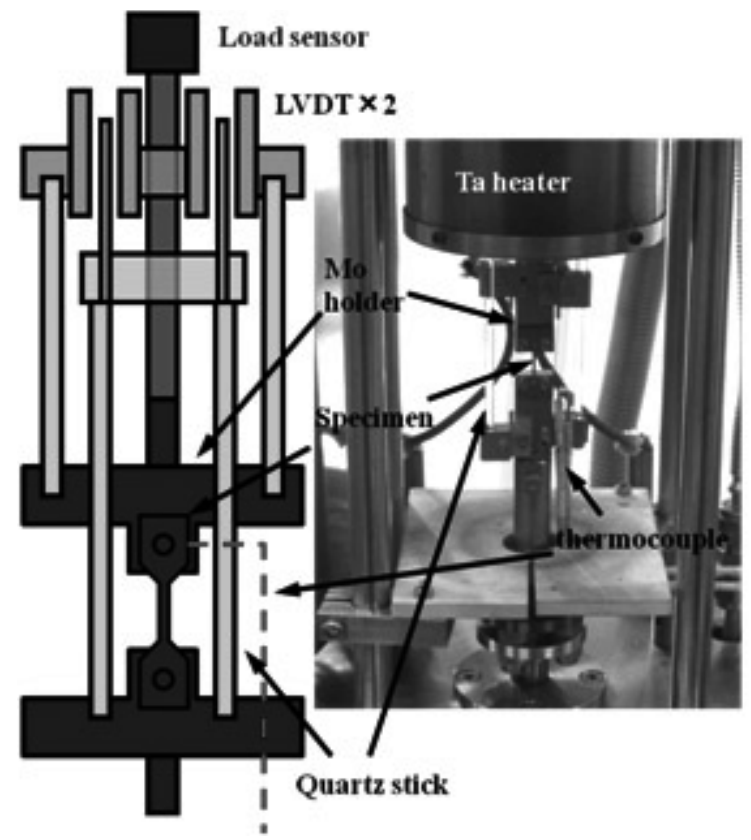

Figure 1: The creep test mechanism and creep machine.

introduced by cold working. Creep strength was defined as an applied stress for a lifetime to $1 \%$ deformation in the present study. The relationship between the applied stress and lifetime was plotted as Figure 2. The results showed that the creep strength of NIFS-HEAT-2 in SACWA state was higher than that in STD and SAACW states at higher stress levels than 180MPa. TEM observation showed high density dislocations in SACWA specimens. Because high density precipitates were observed in SAA state, similar precipitates were expected to form with the dislocations in SACWA specimens. This could be the main reason of the further strengthening in SACWA state. SACWA strengthened SWIP-11 more than NIFS-HEAT-2. This might be due to more Ti-CON precipitates by mainly the higher oxygen concentration in SWIP11.

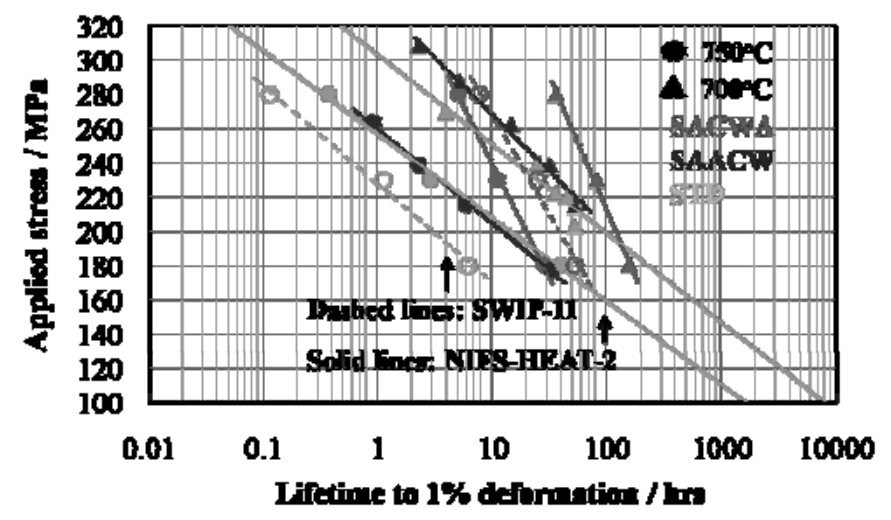

Figure 2: Relationship between applied stress and lifetime to $1 \%$ deformation. 